

\section{Taylor \& Francis Not for distribution}




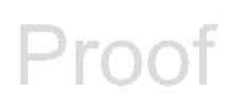

19

\title{
Complexity, mobility, migration
}

\author{
Jan Blommaert, Massimiliano Spotti, and Jef Van der Aa
}

\section{Introduction and definitions}

We start by taking the reader through what superdiversity means and why we believe that a research orientation on migration and mobility needs these days to keep itself occupied with superdiversity. The term superdiversity refers to the 'diversification of diversity' that occurred after the end of the Cold War, and is characterized by different and intensive flows of migration - more people moving from more places towards more places (Vertovec 2007) - combined with the generalized spread and deployment of internet-driven and long-distance information and communication technologies (ICT). More than merely capturing the recent diversification of diversity and situating its onset in global history, superdiversity has the potential to become an emerging perspective on change and unpredictability in ever more intensively encroaching social and cultural worlds (Arnaut 2012). While the first force - new migrations - caused a rapid escalation of demographic diversity in centers all over the world, the second force - mobility through ICT - has shaped new environments for communication and identity development wherever it is used. The combination of both forces leads to rapid and relatively unpredictable social and cultural change a stage of acceleration and intensification in globalization processes raising fundamental challenges for the ways in which we imagine societies, human beings and their activities (cf. Eriksen 2001; Arnaut and Spotti 2015). In this capacity, the emergent academic discourse around superdiversity aligns itself with critical perspectives in transnational studies which reject simplifying and reifying schemes for the complex realities along national and/ or ethnic lines - denounced as "methodological nationalism" (Wimmer and Glick-Schiller 2003) and the "ethnic lens" (Glick Schiller 2007), respectively. Thus, superdiversity as an emerging perspective "denies the comfort of a set of easily applicable assumptions about our object, its features and its meanings," which has two profound methodological consequences: (1) we see 'complexity', 'hybridity', 'impurity', and other features of 'abnormal' sociolinguistic objects as 'normal'. (2) The uncertainty brought to bear by this emergent perspective compels us towards a (linguistic) ethnographic stance, in which "we go out to find how sociolinguistic systems operate rather than to project a priori characteristics onto them" (Blommaert 2015: 84). 
Jan Blommaert et al.

Taking a lead from important predecessors in migration studies (cf. Squires 2005), superdiversity develops from a research tradition that has its solid roots in British social theory and cultural studies about 'new identities' and 'new ethnicities' (cf. Hewitt 1986; Mercer 1994; Hall 1996 and more recently revisited by Harris and Rampton 2010). Further, Blommaert and Rampton (2011) and Rampton (2013), as well as Amin (2012) and Wessendorf (2013), argue that a superdiversity perspective pushes sociolinguistics and other disciplines to move away from 'groupism' as well as from the old binary oppositions between 'host majority culture' versus 'immigrant minority culture(s)', autochthonous versus allochthones and central versus peripheral. In contradistinction, superdiversity and its emergent discourse(s) hinge heavily on the metaphor of historicized simultaneity as exemplified for instance in (1) 'multiple embeddedness' of migrants who form networks of bonding and bridging AuQ33 social relations across multiple social fields (see Rigoni and Saitta 2012; Spotti 2015) and (2) intersectionality, here understood as:

the complex, irreducible, varied, and variable effects which ensue when multiple axis of differentiation economic, political, cultural, psychic, subjective and experiential intersect in historically specific contexts.

(Brah and Phoenix 2004: 76)

Complexity is the keyword for superdiversity on the ground, as it involves perpetual and very rapid social and cultural change bringing under the lens of ethnographic enquiry the repositioning of groups and individuals in socio-cultural spaces that through a group-based approach were thought to be places where diversity had crystalized, for example, 'immigrant neighborhoods'. While the general vector of change may be identifiable - for instance, a tendency towards densely polycentric and multiscalar social spaces - its precise determinants and forms cannot be a priori established (Blommaert, Collins, and Slembrouck 2005; Blommaert 2013; see Waddington 1977 and Prigogyne and Stengers 1984 for inspiration). Further, in our uptake of the term 'complexity', we want to stress that it is not our intention to explicitly engage with chaos theory. Rather we wish the reader to see it as "a source of inspiration which offers us a reservoir of alternative images and metaphors" and that can "help us to reimagining sociolinguistic phenomena - not a fixed and closed doctrine which must be 'followed'" (Blommaert 2013: 15).

All this raises a number of fundamental methodological challenges, questioning a legacy of structuralism in our fields of study and dislodging several of the key notions we traditionally apply from within a fundamental imagination of the social world as stable and categorical (think of notions such as "speech community," Rampton 2000, or the notion of "language" itself, Agha 2007). This fundamental imagination has affected the tools we preferably deploy in analysis, the assumptions underlying it, and the phenomena and processes we choose to take as our object of inquiry. This chapter intends to contribute to such re-imagination, and we will seek inspiration in almost forgotten work: that of the symbolic interactionists.

In what follows, we do three things. First, we argue that a sociolinguistics of migration addressing superdiversity needs to address the real complexity of communicative situations as its object. Further, we argue that it should strive to document such complex situations in some detail, and third, we show how this sociolinguistics may produce new methodological approaches in which change, not synchronic state of events, becomes the central object of inquiry. 
Complexity, mobility, migration

\section{Overview}

\section{The neglected complexity of socio-communicative situations}

In a paper written over half a century ago, Goffman (1964) suggests that the act of speaking needs always be referred to the state of the talk that is gradually unfolding and that is sustained through particular turns at talking but also through particular processes of ratification, or lack thereof, from others than the participant (cf. Blumer 1969). As we learned from the symbolic interactionist school, of which Goffman was a prominent member, interaction is a socially organized practice in which society itself is being 'made', so to speak (Blumer 1969), and this is so not only in terms of who speaks to whom in what language but as a system of mutually ratified and ritually governed actions. In order to gain a better understanding of how meaning is constructed through the mechanisms and strategies of talk in interaction, it is important to take into close examination how voices of participants in talk strive to intermingle. One way of understanding the shifting qualities of individual voices as multiple agencies or roles provided by Goffman (1981) is the concept of participation framework (based on the distinction between author, animator, and principal). At the same time, as it has been pointed out by Blommaert (2005) and Couldry (cf. 2010 for his most recent work on culture and politics after neoliberalism) voice - here understood as someone's capacity of making him/herself understood - is what really matters. That is, although we all have a voice when we talk, we all need to know that our voice matters, that our voice has legitimacy, that it is taken up by the other party involved in the communicative act and that therefore it becomes recognized as valid currency for the trading taking place in the communicative interaction at hand. Hence, following Wertsch (1991), we need to realize that in internalizing forms of social interaction, the individual takes on and interrelates with the voices of others, which accounts for the complexity of 'multi-voiced' dialogues. While joining in a dialogic polyphony of voices, each voice shares a particular experience, viewpoint, or set of attitudes to reality, all of which are instrumental in shaping actions, interactions and relationships (cf. Blumer 1969).

As a result, the situation in which dialogue takes place is also the locus where different beliefs, commitments, and ideologies come into contact and confront each other through the intersecting voices of the participants. Dialogue is also the place in which categorization takes place and where the establishment, negotiation, and rejection of categories happens. This, of course, does not imply that the meaning of categories during a dialogical situation, as that of a talk, is established afresh each time. Rather the establishment, negotiation, and possible acceptance or rejection of what a certain category means, for example who is considered to be a truthful member of a given group, are all actions that are made possible by shared structures of meaning which are established, produced, and negotiated in social inter-

AuQ36 action. Duranti and Goodwin (1994) but also Sarangi and Roberts (1999) use the notion of extra-situational context when they wish to refer to that layer of context that involves the use of social, political, and cultural discourses within which a societal encounter is taking place.

'Extra-situational', however, is a questionable term. In his 1964 paper, Goffman cautioned his generation of scholars against "the neglected situation." That is, the focus on specific parts of speech and on how they affect communicative outcomes - Goffman argued - often bypasses the complexity of the "social situation." The latter gets treated in "the most happy-go-lucky way," in an "opportunistic" fashion; "an implication is that social situations do not have properties and a structure of their own but merely mark, as it were, the 
Jan Blommaert et al.

geometric intersection of actors making talk and actors bearing particular social attributes" (1964: 134). Goffman underscores that "your social situation is not your country cousin" (1964: 134): familiarity with social situations does not mean that they are fully understood. Rather, specific research into the social situation is required as part and parcel of the object of analysis and not just as its 'context'. Goffman defined a social situation as "an environment of mutually monitoring possibilities anywhere within which an individual will find himself accessible to the naked senses of all others who are 'present', and similarly find them accessible to him" (1964: 135). Such meetings of humans in time and space provoke complex sets of rules for coordinating the joint social activity - of talk, but also of gaze, relative body posture, and so forth. And as we know, it is precisely such complex forms of social work where the zone in which Goffman preferred to do his work lies. Recently, another prominent member of the same symbolic interactionist movement, Howard Becker, added precision to Goffman's exhortation:

Everything present in or connected to a situation I want to understand should be taken account of and made use of. If it is there, it is doing something, however unimportant that thing seems, no matter how unobtrusive it is. [. . .] the things I've left out could well be the center of my analysis.

(Becker 2014: 3)

Goffman's and Becker's statements are separated by half a century of social change in which the patterns and modes of communication have dramatically changed. The tremendous complexity of face-to-face interactions described by Goffman have been complemented by the spectacular rise of online and long-distance interaction in which physical spatiotemporal co-presence is no longer a condition for creating social situations. If anything then, and keeping in mind what we said earlier about superdiversity, Becker's echo of Goffman's words is even more acutely relevant, in that social situations of human communication have acquired a bewildering variety in modes, media, scope, formats, genres, and whatnot. And yes, Goffman's complaint about the "happy-go-lucky" ways of addressing such complexities is still valid. Now even more than fifty years ago, "your social situation is not your country cousin."

All of this calls for a fresh uptake in the investigation of social situations that either involve or are a by-product of communicative interactions where complexity is the empirical outcome that we ought to study. The recipe is actually quite simple: since complexity involves a lack of presupposable features in social events and their outcomes, a meticulous ethnographic approach, following Becker's adhortation, is the research approach that guarantees best outcomes; methods in which a lot is presupposed - categories, event templates, roles for actors - run huge risks of missing the point. Mensaert (2013), for example, has shown how in times of superdiversity, using templates (here in social work) requires an enormous and time-consuming effort of the participants in order to build consensus and to come to a mutual understanding, if at all.

To shed light on this increased complexity and show how the latter cannot afford to neglect 'stuff', we present two cases, both of which highlight the presence of online events that are latently present but suddenly manifest themselves in the 'social situation' at hand. The interpenetration of online and offline interaction practices complicated the 'situation', which, as we know, Goffman saw as primarily organized around physical co-presence in a material, shared and, therefore, invokable context. The fact now is that offline, 'real' interactions are infused with online pre-supposable and invokable information and/or are blended 
with online interactions in ways that demand careful inspection and invite analytical and methodological reflection.

\section{Issues and ongoing debates}

\section{A neglected socio-communicative element in an asylum seeking procedure}

Asylum seeking has become one of the dominant modes of migration in the age of superdiversity. The Belgian Asylum procedure is a legal-administrative procedure in which applicants have to explain their motivation for seeking asylum in Belgium. In this procedure, the applicant has to deliver a series of facts about him/herself, explain with a certain degree of plausibility the reason why s/he has left the country of origin and, through that, he has to prove whether he really is from where he claims to be coming (Maryns 2006). As for Belgium, this procedure includes many governmental gatekeeping institutions, each of which has its specific duties and regulations to follow. Among these, the one on which we focus here is the Commissariaat Generaal voor de Vluchtelingen en de Staatlozen (General Commissioner's Office for Refugees and Stateless Persons, or CGRS), which is an independent asylum authority authorized by the Belgian federal state to scrutinize and examine asylum seeking applications. It follows that gatekeeping institutions - like this one - are places where the voice of the asylum seeking applicant finds itself confronted with the institutional voice of the officer(s) that is assessing his/her case. In there, the communicative situation that unfolds is expected to follow clear patterns of questioning as well as clear patterns of answering along the institutionally favored matrix of what is considered a valid proof of identity knowledge. Consequently, the applicant does not only need to understand what to speak about, it also means that the applicant - in order to fit the institutionally held frame of

AuQ37 valid knowledge (cf. Bohmer and Shuman 2011) - should strive to match the same register used by those who are asking the questions. These registers, within social interaction, play a significant role in the processes of origin assessment in that they enable to anticipate the category to which an applicant belongs according to the attributes of his/her story. As Goffman shows us:

we lean on anticipations that we have, transforming them into normative expectations, into righteously presented demands. [. . . It is when an active question arises as to whether these demands will be filled] that we are likely to realize that all along we had been making certain assumptions as to what the individual before us ought to be members of a society.

(Goffman 1963: 2)

Asylum applicants can either (re)produce, negotiate, or dodge their way through these normative expectations (Jacquemet 2015). In light of this, the question of legitimacy, performance, and responsibilities is pivotal in the examination of this social situation and of how it folds in within a specific institutional setting, like the one that is our focus here. Yet again, as Goffman, Blumer, and Becker caution us, all communicative situations constitute a reality sui generis where everything present or connected to the situation, whether online or offline and whether insignificant or unobtrusive at that time, has the potential to become central to the analysis. In what follows, we focus on two things. First, we zoom in on an unschooled young man, whom we call Bashir, who arrived as an asylum seeker in Belgium in February 
Jan Blommaert et al.

2012 and who claims to be from Guinea. Second, we examine how Bashir's claims were judged as untruthful by the authorities because of a register mismatch in the process of naming things that an inhabitant of Conakry, the capital of Guinea, should know.

We focus on what the authorities have made available to us: the letter that Bashir received reporting the result of his application as well as the reasoning employed by the authorities for dismissing his asylum request. The text in question is a re-entextualization of the contents of the long interview and it works as summary of what Bashir has failed to prove during the interview (Blommaert 2001a). That the Belgian institutional agencies do take good care of guaranteeing the asylum applicant with employees who are following a precise code of conduct is a well-known fact. That the Belgian asylum agencies ask for the interview itself to be adapted to the background of the applicant is also true. On the CGRS guideline for the conduct of interviewing, it asserts that "the questions asked and the information given during the interview take into account the asylum seeker's personality, experience and cultural

AuQ39 background (age, gender, health, education level, religion, etc.)" (CGRS 2011: 13). Bashir's officers, who also write the letter of approval or rejection including the motivation for their decision, should take into consideration this series of societal and background variables and fine-tune their questioning toward these variables. Due to his lack of literacy skills, the letter Bashir had received was read to him by his roommate whose name is Majid, a well-educated Guinean coming from a family that counted three generations of local Koranic preachers settled in the area of Télimélé. The letter, in French, indicated by the authorities as the favored language by Bashir for handling legal matters, ${ }^{1}$ reported that after having questioned him and having taken into account Bashir's educational background, his application was rejected.

Bashir's story is a narrative that is a (more or less straightforward) representation of a segment of someone's social life in such a way as to render it according to a series of facts

AuQ40 ordered in time and space (cf. Bauman 1986). As many other asylum seeking applicants, Bashir too had to render his life prior to coming to Belgium in a sequence of events. In his reconstruction, we understand that Bashir is the son of a Malinka-speaking father and a Peul-speaking mother. Although raised as a speaker of Peul, the mother tongue attributed to him by the Belgian authorities was Malinka. Because of inter-ethnic conflict between his family members, he had lost his father, who was beaten by his mother's brothers and died of his injuries. At this point, Bashir's mother had put him in the care of a Guinean police officer, a friend of his late father, to protect him from the internal family struggles. Shortly thereafter, this police officer had him leave for Europe. Like all asylum seekers claiming their identity, Bashir had to prove that he really was who he said he was. In other words, he had to prove that he was from the country he claimed to be from, as well as from Conakry, the city in which he claimed to have been living with his family.

An asylum interview is an administrative task that requires quite some skillful knowledge of genres from the side of the applicant (see Blommaert 2001a: 211-245; Maryns 2006). In conducting them, immigration authorities typically start from the premise that if someone claims to be from a certain country then s/he has to know facts about that country and the exact place where s/he claims to be from. It is solely by their knowledge of certain factswhether they are political, social, urban, or relating to popular culture that asylum seekers stand a chance. Their knowledge of these facts is seen both as a confirmation of their identity and the stuff of moral judgment (i.e., their trustworthiness). The sequence of inferences goes along the line of: the applicant did not tell lies, ergo, he is who he claims to be, ergo, he is morally righteous, ergo, he can be granted permission to stay in country $\mathrm{X}$. When we turn to the summary drawn up by the authorities after the long interview, Bashir has failed to prove 
himself on many things. He failed to provide the correct answers to a number of pertinent questions that ranged from the name of the only bottled water sold in Guinea to the name of players that were part of the Guinean national football team. Further, he was not able to name the radio channels he listened to and he was happy to limit himself to the sentence " $\mathrm{j}$ 'écoute la musique" ("I listen to music").

What comes across as most striking is the lack of knowledge attributed to Bashir by the authorities when it comes down to name the mosque where he claimed to have gone to for Qur'anic instruction. It is true that Bashir did not know the name of this mosque; during the interview he simply stated that he went "à la grande mosquée" ("to the big mosque"). What exactly Bashir did not know about the mosque then was its official name, Mosquée du Faycal-another piece of information that the authorities obtained from the web, retrieved from holiday websites (see http://www.petitfute.com/ and http://www.aminata.com/) aimed at adventurous westerners who want to know all about the sights to see in Conakry.

In fact, the country information used in the interviewer's checklist was obtained from two major sources: information provided by other applicants and bona fide translators, and information obtained from widely accessible web sources such as Wikipedia and travel websites. The broad availability of such online information grants it the status, in the interviewers' eyes, of pre-supposable (i.e., widely shared and low-threshold) 'truth' and ends up operating in a totally different epistemology than that of the interviewee which leads to difficulties in building consensus and to the subjugation of the interviewee's frame by the interviewer. The argument runs, in fact, as follows: if you're really from place X, you should know these widely known facts. Note here how online resources change and determine the epistemic regime within which asylum interviews evolve, allowing distinctions and degrees in knowledge that become institutionally consequential - they determine the credibility of the applicant's identity claims.

What are we left with then? A register discrepancy and a lack of voice, in that the voice of Bashir did not perform the function that these websites, the neglected element in the communicative situation, made pre-supposable. The text of the letter redacted by the authorities encapsulates how the applicant repeatedly fails to speak real 'country talk' and to match the register that is expected from him, that is, the register he should draw upon in order to have his voice recognized by the authorities as indexing his essence of truthfully being from Conakry. Bashir, although illiterate and unschooled is for the authorities, a case, a file number and, as such, someone who should keep it real, someone who within the long interview had to show his knowledge. The letter, therefore, provides us with a glimpse of an omnipresent autocratically issued register, based on facts elected as true by the authorities because these authorities have espoused yet another doxa, the one that associates something on the web as something credible.

The web is the external agent neglected in the social situation at hand. Methodologically speaking, the web becomes central to the neglected situation and core element in the analysis. The web, in fact, becomes that external agent that although not synchronically co-present during the interview is still present enough to be considered as source upon which to gain yet another piece of information, possibly the biggest piece, that determines Bashir's lack of knowledge and that contributes to dismiss his identity claims and, by extension, his asylum application. Online sources here are a distant participant, so to speak, contributing 'frames' of pre-supposable and inferable knowledge to the ongoing interaction. They are very much part of the "empirical world" (Blumer 1969: vii) of asylum application procedures and demand analytic attention as such, for it is not just part of the "text trajectory" of AuQ41 bureaucratic procedure (Briggs 1997; Blommaert 2001b) but also appears as an immediate 
Jan Blommaert et al.

factor in the interaction processes - the on-the-spot ratification processes that determine a procedure outcome. The actual meaning attributed by participants in an interaction to places, people, and events mentioned and used in calibrating each other's stance and the access to such sources as well as the ability to deploy them competently shapes a structured inequality in the kinds of bureaucratic encounters we discuss here. They shape, in other words, the participants themselves as people who construct, anticipate and reconstruct each other's meanings in interaction. The next research example will take this point further.

\section{A neglected socio-communicative element in social work}

Research on the trajectories of migrant families in the Belgian welfare system has led us to Nabijah, a 37-year-old Belgian-Iraqi woman living in Antwerp North (see Van der Aa and Blommaert 2015 for a more elaborate description of this case). At the time of the research, Nabijah was living with four children in a very small apartment where irregular heating and electricity depended on what was left on the budget meter (a sort of prepaid gas/electricity system). One of the children was mentally disabled and the oldest child was not hers, but the child of her sister who lived in Germany. Having gone through a very rough and violent divorce from her Belgian/Iraqi husband, Nabijah ended up as a single mom in harsh poverty. Most bills were handled by a lawyer which immediately had to pay off the accrued debt of the (by then) imprisoned husband and various other bills, leaving Nabijah with a mere $€ 7$ a day to take care of five people. A typical dinner in the household consisted of a large can of baked beans in tomato sauce and an equally large cheap bag of salted potato chips, followed by an apple.

Nabijah and her children were monitored and followed up by Lucy, one of the care providers at the Circle, an Antwerp welfare institution dealing with children and adolescents aged 6-18 and their families, after a transfer from court. Reasons for such transfers could be criminal activities of the youngsters; issues of violence, abuse and neglect; issues of extreme poverty, and so on. The transfer is obligatory (parents cannot refuse the help from the institution) and is often a final way to avoid the children being placed in care. At the time of the research, Lucy had weekly meetings with Nabijah in her home, often together with various other people, such as social workers, lawyers (to take care of the debt that remained after the divorce), teachers, the care provider(s) of her mentally handicapped son (who lived in a residential care institution during the week) and translators. During a period of several months one of us (Jef Van der Aa, henceforth JVDA) accompanied Lucy to Nabijah's house, taking part in at least fifteen home visits of one and a half hour each. All conversations were tape recorded and conducted in Dutch, often mediated by an Iraqi or Moroccan Arabic translator. We complemented the audio recordings with the intensive taking of field notes. It is in this context that we want to discuss the importance of 'what was left out' which in some cases may actually "be or become the center of our analysis" (Becker 2014: 3) and how we can engage with this "not-said but still-there" (Kulick 2005).

Let us have a closer look at a Goffmanian 'situation' in Nabijah's case. At one point, approximately nine weeks into JVDA's involvement with Nabijah and her family, Lucy, the translator and JVDA arrived at Nabijah's apartment for the weekly visit. There had been a traffic jam so we came in a little late. Nabijah appeared not to be home and we thought perhaps she too had been caught up in traffic, as even trams and buses were blocked from passing through the road works. We waited for several minutes, knocked the door several times, shouted her name and so on. A little while later, someone stumbles to the door in a rush. It was Nabijah, with her laptop in hand, a very heavy object that was at least seven 
years old, and whose weight usually caused it to sit on an equally old folding chair next to where Nabijah was seated during our conversations. We came in, were seated across from Nabijah, as she held the laptop in her hands. She said "I was doing things on the computer, therefore I didn't hear you guys." It seemed the folding chair was destroyed, as some of the cloth was torn apart and one of its chair legs was sticking out.

The translator, being from Iraqi descent this time, and alternating with a Moroccan one for 'reasons of planning', translated in spoken Iraqi Arabic vernacular. For weeks, Nabijah had been 'stalking' Lucy about helping her with her travel passport, which seemed, for several reasons, quite hard for her to obtain. Nabijah had been married in Lebanon with her former husband, who had a double Iraqi/Belgian nationality through which Nabijah and her children had been able, eventually, to obtain Belgian nationality.

At one point, we were discussing the problem very concretely, as a negative advice regarding the passport had come in from the local authorities because of her former husband's legal trouble. The translator carefully explained the problem to Nabijah, and at the same time commenting on an appeal form Lucy had brought. Being heavily involved in the conversation, and in order to pinpoint all kinds of issues Nabijah seemed to have with the form, she had put the laptop on the floor behind her, not next to her as usual since the chair was broken. Suddenly a voice shouted something from behind Nabijah. Lucy and JVDA were both surprised, and the translator replied to the voice on the computer, telling us that it was Nabijah's brother, listening in on Skype. Nabijah confirmed this and explained that he was reacting to the information with regards to the travel passport. There had been a request from the brother to formally adopt his son, Nabijah's nephew. Nabijah then showed us the brother, we waved at him, and he disappeared from Skype as swiftly as he came once the conversation took another direction. Nabijah needed the passport in order to go and arrange things in Iraq to make the adoption possible. Also, it turned out that the brother had been listening in quite regularly in the weeks before and thus the prioritization of the travel passport and other adjacent issues was suddenly seen in a whole new light. The conversation had been regularly 'steered' for several weeks by the non-speaking but still present brother: the co-presence of online and offline interaction, sometimes manifestly present, sometimes latently lurking.

What we observed here was an extremely complex interactional situation which cannot be analyzed synchronically. We observed something like a 'total social fact' in which online and offline events merged, latent objects suddenly became manifest, and a complex interaction of linguistic, generic, cultural, and religious resources took place (Van der Aa and Blommaert 2015). Silverstein's (1985) concept of the 'total linguistic fact' can be expanded to the analysis of superdiverse settings in which the 'neglected' becomes the center of attenAuQ42 tion (Becker 1964):

The total linguistic fact, the datum for a science of language is irreducibly dialectic in nature. It is an unstable mutual interaction of meaningful sign forms, contextualised to situations of interested human use and mediated by the fact of cultural ideology.

(Silverstein 1985: 220)

Another key point here is the co-incidental nature of the 'discovery' of the neglected element: the fact that the chair was broken by which the 'unimportant' laptop drew our attention, the brother being 'sidetracked' from the ongoing 'show' by being placed behind the chair, the suddenly intruding 'voice' of the brother, us being late causing Nabijah to have embarked in 'full conversation' with the brother, the translator being Belgian Iraqi (from the 
Jan Blommaert et al.

same region of Nabijah and actually vaguely knowing the family in Iraq) instead of Moroccan so that she could recognize local vocabulary, and so on. The social situation deserves analysis in its own right (Goffman 1964: 134) and all conversations contained within it are to be interpreted through many layers of fairly coincidental historicized social frames. This coincidence shouldn't worry or demoralize us, as important manifestations of these latent frames will be repeated over and over again. Therefore, sustained attention to these always slightly different manifestations will do the trick, hereby making change itself our object of analysis.

Nabijah's story, her life, her issues and her problems were necessarily reduced in the professional vision of the social worker, in order to deal with those issues the institution was professionally and legally allowed to handle. Nabijah is a 'case', has a 'file' and belongs to one or more 'problematic' social categories for which she needs 'treatment' and 'help'. Thus, the social work frames have been pre-configured and only particular elements that fitted that professional scheme were accepted as meaningful. The point we have made so far, following social interactionist sources of inspiration is that for the ethnographer, everything is potentially meaningful. Latent objects can become manifest at the blink of an eye, and this is something we cannot afford to ignore, neither as ethnographers with an academic purpose, nor as societal actors (such as social workers) with a socio-psychological, legal and human finality. The latter simply cannot afford anymore to neglect aspects of the situation that cause an entire analytical trajectory of Hineininterpretierung (or predisposed interpretation), lest the consequences of the neglect may be detrimental to the human beings in care, or may even become matters of life and death (see Joseph's case in Blommaert 2009). In Nabijah's case, it turned out that she did not really want to adopt the son, and that the pressure being put on her shoulders to do so anyway had been heavily impeding the attention for her other children (the key mandate of the social workers) and her own health. This resulted in severe anxiety attacks and the overusage of benzodiazepines whose nasty side effects prevented her from working on a regular basis.

But social workers have not been trained to pay attention to such analytic detail, and could benefit on such occasions from an extra pair of anthropological eyes. The exchange is mutual; as ethnographers should involve themselves in those cases deemed analytically relevant by societal actors themselves. These actors can often pinpoint things that are 'weird', 'out of routine', in other words, brief manifestations of the neglected aspects of a particular situation. Lucy had found Nabijah's communicative behavior become increasingly 'strange' over the last few weeks and had asked me along to do the case study. It is exactly there that we come in as ethnographers. Our role has changed from being a mere 'observer' who describes what he or she sees, to an 'active participant' who

AuQ43 makes explicit the changes for which there is no vocabulary yet. In this spirit, Hymes (1980) developed a research program called 'ethnographic monitoring'. This consists of the following steps: (1) ethnographers consult social actors to identify what issues concern them most (the 'other's position); (2) observe behavior relevant to that issue in a series of contexts in which the participants are engaged (observer's position); (3) share back their findings with the participants (instant as well as more long-term feedback and uptake); (4) take stock of findings (evaluating 'effect'). We are convinced, with Hymes, that by following these steps, there is a guarantee that research plans and programs are developed organically, and in close consultation with all social actors involved. In other words, static solutions are being replaced by complex dynamics, because understanding the world involves changing it (for more on this type of 'ethnographic monitoring', see Van der Aa and Blommaert 2015). 
Complexity, mobility, migration

\section{Future directions}

\section{How not to neglect what has been so far neglected}

In a celebrated text often considered the definitive statement on symbolic interactionism, Herbert Blumer mentions:

the fact that the empirical world can 'talk back' to our pictures of it or assertions about it - talk back in the sense of challenging and resisting, or not bending to, our images or conceptions of it. This resistance gives the empirical world an obdurate character that is the mark of reality. [. . .] It is this obdurate character of the empirical world - its ability to resist and talk back - that both calls for and justifies empirical science. Fundamentally, empirical science is an enterprise that seeks to develop images and conceptions that can successfully handle and accommodate the resistance offered by the empirical world under study.

(Blumer 1969: 22-23)

Blumer directs us toward a crucial theoretical problem for the study of language in society: to define our own 'empirical world' in an age of intense and rapid change in the empirical world in which, consequently, 'talking back' may be the rule rather than the exception, and as such we need to adopt methodologies such as 'ethnographic monitoring' (see earlier) in order to accurately capture these voices. While the field of migration may present us with the clearest and most pressing prompts for reflection, the challenge is probably general: are we sure that our constructions of objects of analysis (the "images and conceptions" referred to by Blumer) match the empirical world and successfully counter its resistance? Concretely, if we are aware of the intrinsic complexity of the social events we are observing, does our analysis bring out and explain this complexity?

The examples we have offered above involved a number of critical moves, the most crucial of which was to redefine the boundaries between what we call 'text' and 'context'. There is a tendency in our fields of study to (1) reduce the notion of 'interaction' as an object of study to the linguistically describable 'text' it involves; (2) possibly complemented by 'paralinguistic' features such as gesture, pitch and so forth, seen as secondary features of meaning; and (3) set this 'text' against a background which we call 'context' and consider relevant only to the extent to which it clarifies the 'text'; (4) where 'situational context' is narrowed down to the here-and-now of interaction. Non-immediate aspects of context, as we have seen, are seen as extra-situational (intertextual or inter-discursive, usually, in Fairclough's 1992 terminology). And finally, (5) we assume that live turn-by-turn interaction in a setting of physical co-presence ('conversation', in short) is the 'natural' object of research, often (6) using a speaker-centered framework of analyzing meaning (for the latter, see Blommaert 2014).

These assumptions, it should be clear, are problematic for several reasons. One, it is best, following several generations of scholars, to define interaction as an activity involving several practices, some of which are 'linguistic' while others have to do with the body, the objects and technologies mediating the interaction, and the space-time frame in which it develops (cf. Scollon and Scollon 2004). The description of Nabijah's case, we believe, made this abundantly clear: people make sense of each other's messages in complex arrays of things, all of which contribute to the 'meaning' produced in interaction. The 'total linguistic fact' is, in effect, the total semiotic fact in which more signs than just the 'textual' ones are being exchanged, and all of these signs are agentive in the construction of meaning 
Jan Blommaert et al.

outcomes (which explains, for instance, why interviews gathered at a railway station during rush hour are, as a rule, shorter than interviews gathered in a shopping area on Saturdays). Online sources and tools are inevitably included in these categories, and their dislodging effects on our standard tools of description must be addressed.

Second, a crucial agent in the production of meaning is knowledge, and sources of knowledge, or technologies of knowledge, are often dismissed without much substantive argument as mere background factors to be enacted in what really matters: the interaction itself. Paradoxically, it is the analysis of interaction itself that defies this assumption, for the work of interaction involves complex patterns of decoding and uptake of knowledge - which is the point of interaction (cf. Cicourel 1972). Furthermore, what happens in interaction can often only be explained by asymmetries in accessible knowledge; Bashir's case clearly demonstrated this. And even if such sources of knowledge and their distribution patterns are situated, strictly speaking, 'outside' of the moment of interaction (and often belong to the 'structural' scale-levels of social organization), they operate as agents of meaning in actual moments of interactional deployment. They are part, in other words, of the "participation framework," as the 'frames' on which actual people can draw in communication and, as Cicourel (1972) demonstrated, they tend to affect what we understand as 'rules' and 'norms' in social interaction. A separation between people and the knowledge they carry, consequently, makes little sense when analyzing interaction: the knowledge is a core part of the interacting person. The case of Bashir illustrated, in addition, how asymmetries in accessible knowledge clearly belong to the escalating 'diversity' in superdiversity.

Third, and as an effect of the preceding points, what is commonly understood as 'interaction' cannot be confined to the moment of interactional deployment. 'Local' and 'trans-local' are inaccurate descriptors for defining the dimensions of context in interaction, and ineffective as descriptors of interactional processes themselves. The moments of interactional deployment so favored by conversation analysts (for instance) are never autonomous, but always part of longer social activities of decision-making, opinion-forming or, in its most general sense, the emergence and reproduction of social structure (cf. Agha 2007). And, again, asymmetries in the ways in which moments of interaction are absorbed into these longer and more complex trajectories - think of the logic of bureaucracy in which one step of the process is made with a clear anticipation of the next one - account for much of what happens in moments of interactions. In fact, grasping something as elusive and unpredictable as social and cultural change demands attention, precisely, to differences in 'backgrounds' and 'futures' of people entering arenas of social engagement; a restricted notion of 'interaction' can at best yield a snapshot picture of such larger processes.

\section{Implications}

As we have discussed, the methodological challenges are probably general to all communication, but the field of migration may offer the clearest tests for the analytical frameworks we currently employ. The challenge is to arrive at a holistic mode of analysis that cancels the resistance of the empirical world of migration and interaction - one which avoids the reduction of the complexity it inevitably offers and which, given the inevitability of rapid change characterizing this empirical world, takes little for granted. What is left out, we know, might be the point of the entire thing; so let us not dismiss too many factors in advance, as irrelevant or as things that 'technically speaking' do not belong to our kinds of analysis. There is, at present, not much research that answers the challenges outlined here. This turn - a turn towards a reevaluated epistemology of realism, we would argue - now needs to be taken up in research. 
Complexity, mobility, migration

\section{Related topics}

Translanguaging in mobility

Superdiversity and language

Space, place, and language

\section{Further reading}

Becker, H. (1963). Outsiders: Studies in the Sociology of Deviance. New York: The Free Press.

An early sociological piece documenting the interactional study of people in the margins of society.

Blumer, H. (1969). Symbolic Interactionism: Perspective and Method. Berkeley: University of California Press.

An overview of 'meaning' in interaction, much needed for investigating complex indexically pregnant encounters.

Cicourel, A. (1972). Cognitive Sociology: Language and Meaning in Social Interaction. Harmondsworth: Penguin.

This seminal book presents an array of possibilities to combine research methods in investigating complexity in social life.

Goffman, E. (1964). The neglected situation. American Anthropologist 66/6, Part 2: The Ethnography of Communication: 133-136.

This article concisely comments on important aspects of social life often neglected in interactional analysis.

Kulick, D. (2005). The importance of what gets left out. Discourse Studies, 7(4-5), 615-624.

In this article it is argued that language, interaction and culture as indexicals cannot be reduced to actual observable performance, the 'there' in an interaction.

\section{Note}

1 Please note that there are only two languages assigned to the official written communication between an applicant and the CGRS's authorities, these being either French or Dutch; this is done by institutions so to replicate the ideology of stable bilingualism. In fact, the language ideological debate in Belgium is much more complex than this.

\section{References}

Agha, A. (2007). Language and Social Structure. Cambridge: Cambridge University Press.

Amin, A. (2012). Land of Strangers. Cambridge: Polity Press.

Arnaut, K. (2012). Super-diversity: Elements of an emerging perspective. Diversities 14(2): 1-16.

Arnaut, K. and M. Spotti (2015). Superdiversity discourse. In Tracy, K., Cornelia, I. and T. Sandel (eds.), The International Encyclopedia of Language and Social Interaction (pp. 1-7). Hoboken: Wiley-Blackwell.

Becker, H. (2014). What About Mozart? What About Murder? Reasoning from Cases. Chicago: University of Chicago Press.

Blommaert, J. (2001a). Investigating narrative inequality: African asylum seekers' stories in Belgium. Discourse and Society 12/4: 413-449.

Blommaert, J. (2001b). Context is/as critique. Critique of Anthropology 21/1: 13-32.

Blommaert, J. (2005). Discourse: A Critical Introduction. Cambridge: Cambridge University Press.

Blommaert, J. (2009). Language, Asylum and the national order. Current Anthropology 50(4): 415-441.

Blommaert, J. (2013). Ethnography, Superdiversity and Linguistic Landscapes. Bristol: Multilingual Matters. 
Jan Blommaert et al.

Blommaert, J. (2014). Meaning as a Nonlinear Effect: The Birth of Cool. Tilburg Papers in Culture Studies, Paper 106 [Online]. Retrieved from https://www.tilburguniversity.edu/research/institutesand-research-groups/babylon/tpcs/ [Accessed 30 October 2015]

Blommaert, J. (2015). Commentary: Superdiversity old and new. Language \& Communication 44: 82-88.Blommaert, J., J. Collins and Slembrouck, S. (2005). Polycentricity and interactional regimes in "global neighborhoods". Ethnography 6(2): 205-235.

Blommaert, J. and Rampton, B. (2011). Language and superdiversity. Diversities 13(2): 1-22.

Blumer, H. (1969). Symbolic Interactionism: Perspective and Method. Berkeley: University of California Press.

Cicourel, A. (1972). Cognitive Sociology: Language and Meaning in Social Interaction. Harmondsworth: Penguin.

Couldry, N. (2010). Why Voice Matters: Culture and Politics after Neo-liberalism. London: Sage.

Duranti, A. and Goodwin, C. (1994). Rethinking context: Language as an interactive phenomenon. American Ethnologist 21(4): 919-920.

Eriksen, T.H. (2001). Tyranny of the Moment. London: Pluto Press.

Glick Schiller, N. (2007). The centrality of ethnography in the study of transnational migration. In A. Kumar Sahoo and B. Maharaj (eds.), Sociology of Diaspora. New Delhi, India: Rawat.

Goffman, E. (1964). The neglected situation. American Anthropologist, 66/6, Part 2: The Ethnography of Communication, 133-136.

Hall, S. (1996). New ethnicities. In D. Morley and K.-H. Chen (eds.), On Postmodernism and Articulation: An Interview with Stuart Hall (pp. 441-449). London: Routledge.

Harris, R. and B. Rampton (2010). Ethnicities without guarantees: An empirical approach. In Margareth Wetherell (ed.), Liveable Lives: Negotiating Identities in New Times (pp. 95-119). Basingstoke: Palgrave.

Hewitt, R. (1986). White Talk, Black Talk: Inter-Racial Friendship and Communication amongst Adolescents. Cambridge: Cambridge University Press.

Jacquemet, M. (2015). Asylum and the digitalization of evidence. Paper presented at the Symposium Political Asylum and the Politics of Suspicion, Mershon Centre for International Security, Ohio State University, 23 March 2015.

Kulick, D. (2005). The importance of what gets left out. Discourse Studies 7(4-5): 615-624.

Maryns, K. (2006). The Asylum Speaker: Language in the Belgian Asylum Procedure. Manchester: St. Jerome.

Mensaert, R. (2013). Building and Breaking Frames in Welfare Work. Tilburg Papers in Culture Studies, Paper 75 [Online]. Retrieved from https://www.tilburguniversity.edu/research/institutesand-research-groups/babylon/tpcs/ [Accessed 30 October 2015].

Mercer, K. (1994). Welcome to the Jungle: New Positions in Black Cultural Studies. New York: Routledge.

Prigogyne, I. and I. Stengers (1984). Order Out of Chaos: Man's New Dialogue with Nature. New York: Bantam Books.

Rampton, B. (2000). Speech Community. Working Papers in Urban Language and Literacies, 15 [Online]. Retrieved from www.kcl.ac.uk/ldc [Accessed 30 October 2015].

Rampton, B. (2013). Styling in a language learn later in life. Modern Language Journal 97(2): $360-382$.

Rigoni, I. and E. Saitta, eds. (2012). Mediating Cultural Diversity in a Globalized Public Space. New York: Palgrave Macmillan.

Scollon, R. and S. W. Scollon (2004). Nexus Analysis: Language and the Emerging Internet. London: Routledge.

Silverstein, M. (1985). Language and the culture of gender. In E. Mertz and R. Parmentier (eds.), Semiotic Mediation (pp. 219-259). New York: Academic Press.

Squires, J. (2005). Is mainstreaming transformative? Theorizing mainstreaming in the context of diversity and deliberation. Social Politics: International Studies in Gender, State and Society 12(3): $366-388$. 
Van der Aa, J. and J. Blommaert. (2015). Ethnographic Monitoring and the Study of Complexity. Tilburg Papers in Culture Studies, Paper 123 [Online]. Retrieved from https://www.tilburguniversity. edu/research/institutes-and-research-groups/babylon/tpcs/ [Accessed 30 October 2015].

Vertovec, S. (2007). Super-diversity and its implications. Ethnic and Racial Studies 30(6): 1024-1054. Waddington, C. (1977). Tools for Thought. St Albans: Paladin.

Wessendorf, S. (2013). Commonplace diversity and the "ethos of mixing": Perceptions of difference in a London neighbourhood. Identities 20(4): 407-422.

Wertsch, J.V. (1991). Voices of the Mind: A Socio-Cultural Approach to Mediated Action. Cambridge, MA: Harvard University Press.

Wimmer, A. and Glick-Schiller, N. (2003). Methodological nationalism, the social sciences and the study of migration: An essay in historical epistemology. International Migration Review 37(3): 576-610. 